\title{
Caligopsis seleucida (Hewitson) e seus estágios imaturos (Lepidoptera, Nymphalidae, Brassolinae)
}

\author{
Eurides Furtado ${ }^{1} \&$ Fernando Corrêa Campos-Neto ${ }^{2}$ \\ 1 Caixa Postal 97, 78400-000 Diamantino, Mato Grosso, Brasil. \\ ${ }^{2}$ Rua Corcovado 1030, Bairro Monte Castelo, 32285-000 Contagem, Minas Gerais, Brasil.
}

\begin{abstract}
Caligopsis seleucida (Hewitson) and its immature stages (Lepidoptera, Nymphalidae, Brassolinae). The immature stages of Caligopsis seleucida (Hewitson, 1877) are described from laboratory studies conducted in Diamantino (Mato Grosso) and Contagem (Minas Gerais). The larvae reared in Mato Grosso fed on Phyllostachys aurea A. \& C. Rivieri and Dendrocalanus giganteus Munro (Poaceae), while the other larvae fed on P. aurea and Bambusa vulgaris Schrad. (Poaceae). The ontogenetic development from egg to adult emergence (in Mato Grosso) lasts 115 days when the larvae pass through five instars, and 147 days when there is an extraordinary larval instar. Immatures and adults are illustrated in color.

KEY WORDS. Biology, hostplant, Poaceae, spatial distribution.
\end{abstract}

RESUMO. Os estágios imaturos de Caligopsis seleucida (Hewitson, 1877) são descritos de estudos em laboratório realizados em Diamantino (Mato Grosso) e Contagem (Minas Gerais). As larvas criadas no Mato Grosso foram alimentadas com Phyllostachys aurea A. \& C. Rivieri e Dendrocalanus giganteus Munro (Poaceae), enquanto as outras larvas tiveram como alimento $P$. aurea e Bambusa vulgaris Schrad. (Poaceae). $O$ desenvolvimento ontogênico de ovo até adulto (no Mato Grosso) foi de 115 dias quando as larvas tiveram cinco ínstares e de 147 dias quando tiveram um ínstar extra. Imaturos e adultos são ilustrados a cores.

PALAVRAS CHAVE. Biologia, plantas hospedeiras, Poaceae, distribuição espacial.

Caligopsis foi criado por SEYDEL (1924) para abrigar uma única espécie, C. seleucida (Hewitson, 1877), transferida de Eryphanis Boisduval, 1870. A espécie é considerada rara e é pouco representada em coleções e pouco mencionada na literatura. STICHEL (1909) e Frunstorfer (1924), mesmo com seus vastos conhecimentos de Brassolinae, desconheciam a fêmea, e os machos então conhecidos eram oriundos do Brasil e da Bolívia, sem conhecimento preciso dos locais onde os exemplares foram coletados. Vários autores repetem essas ocorrências, acrescidas de Amazônia, Peru e Colômbia (Seydel 1924, Zerny 1940, Travassos \& May 1941, Blandin 1974, RobBins et al. 1996). D’Abrera (1987) também repete a distribuição já conhecida e ilustra a fêmea a cores pela primeira vez. OTERo \& MARIGo (1992) citam ocorrência da espécie na Serra dos Carajás, Estado do Pará.

Na região do alto Rio Arinos, Mato Grosso, onde o primeiro autor estuda Lepidoptera há 30 anos, somente dois machos de C. seleucida foram encontrados, nos meses de agosto e setembro.

Neste trabalho são descritos e ilustrados a cores pela primeira vez os estágios imaturos desta espécie, e são divulgadas as espécies de bambus oferecidas às larvas como alimento alternativo nas criações em cativeiro. Continua desconhecida a planta hospedeira natural, que com muita probabilidade deve ser uma ou mais espécies de Poaceae, sobretudo bambus.

\section{MATERIAL E MÉTODOS}

O material estudado procede da Serra dos Carajás, 600 m, Parauapebas, Pará, Brasil.

Para oviposição, o segundo autor aprisionou fêmeas em sacos plásticos e obteve posturas mesmo sem folhas da planta alimentícia junto à fêmea. As larvas que foram utilizadas neste estudo foram criadas no Mato Grosso, em viveiros montados envolvendo ramagens vivas da planta alimentícia. Em Minas Gerais usou-se caixas plásticas com pequenos furos na tampa para parcial ventilação, com troca da planta em dias alternados. O desenvolvimento das larvas, bem como o ciclo de ovo até imago, foram semelhantes nas duas experiências.

\section{Morfologia dos imaturos}

\section{Ovo (Fig. 1)}

Globular, com estrias verticais, pólos deprimidos; branco na postura, se fértil torna-se levemente rosado, com manchas polimórficas avermelhadas. Diâmetro 2,2 mm. Período embrionário 11 dias. 

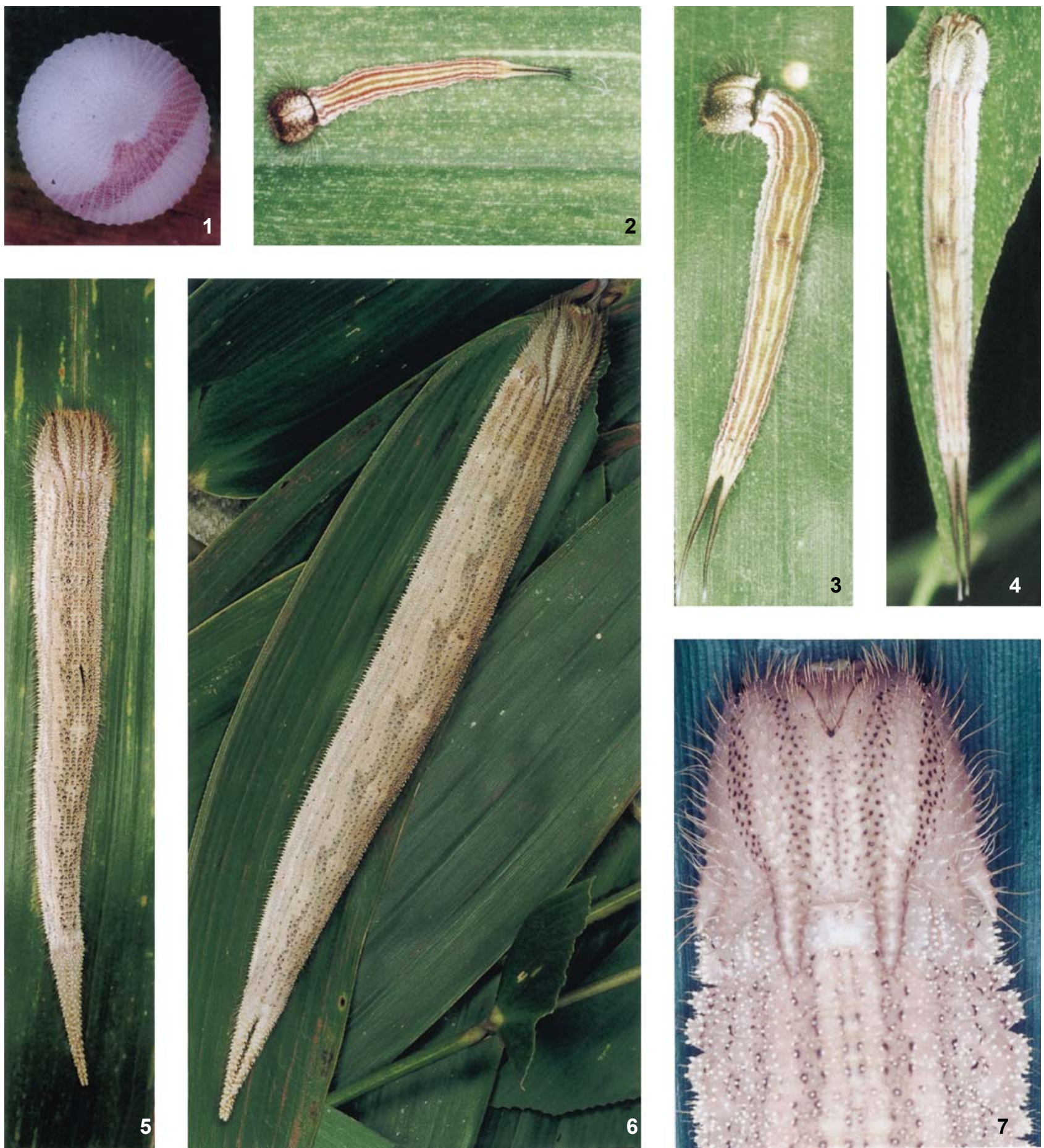

Figuras 1-7. Caligopsis seleucida: (1) ovo; (2-7) larva: (2) $1^{\circ}$ ínstar, vista dorsal; (3) $2^{\circ}$ ínstar, vista dorsal; (4) $3^{\circ}$ ínstar, vista dorsal; (5) $4^{\circ}$ ínstar, vista dorsal; (6) $5^{\circ}$ ínstar, vista laterodorsal; (7) cabeça e parte do tórax da larva de $5^{\circ}$ ínstar, vista dorsal.

Revista Brasileira de Zoologia 21 (3): 593-597, setembro 2004 


\section{Larva (Figs 2-8)}

Primeiro ínstar (Fig. 2). Cabeça arredondada, região ventral deprimida; revestida com cerdas castanho-escuras na metade ventral e mais claras no restante; regiões ventral e occipital castanho-escuras; áreas oblongas castanho-claras no vértice e lateralmente; também, desta última cor o frontoclípeo e adjacências; mandíbulas e estemas pretos. Tegumento amarelo-claro com três estreitas faixas longitudinais avermelhadas, nas áreas supra-espiracular, subdorsal e dorsal. Faixa espiracular esbranquiçada. Área subventral avermelhada e a ventral oliváceo-clara. Pernas torácicas, abdominais e anais acinzentado-claras, semi-translúcidas. Placa suranal bífida, com os prolongamentos castanho-claro dorsalmente na metade basal e preto no restante, com uma longa cerda branca apical. Comprimento da larva ao eclodir $8 \mathrm{~mm}$; no final do ínstar 15,5 mm. Duração 11 dias.

Segundo ínstar (Fig. 3). Cabeça oblonga, dorso-ventralmente deprimida, castanho-clara com áreas pretas oblongas laterais formadas com sulcos circulares; também de coloração preta toda a área ventral, sutura occipital, mandíbulas, estemas e a metade posterior da fronte. As cerdas são esbranquiçadas e pouco mais esparsas que no ínstar anterior. Três pares de escolos posteriores, direcionados para trás, dispostos nas regiões dorsal, laterodorsal e látero-ventral. Corpo semelhante ao ínstar anterior; as faixas longitudinais castanho-avermelhadas, a supraespiracular mais estreita que as demais; A3 com verruga e mancha escura na linha dorsal próximo à borda posterior; prolongamentos da placa suranal castanho-escuros com pequenos espinhos pretos na porção maior e brancos nas pontas. Comprimento $22 \mathrm{~mm}$. Duração 13 dias.

Terceiro ínstar (Fig. 4). Difere do ínstar anterior pela coloração geral da cabeça mais clara, marrom; cerdas mais abundantes e claras; escolos maiores, cônicos, pontiagudos, os anteriores aproximadamente $1 / 3$ do comprimento dos dorsais; tegumento de aspecto granuloso, cinzento-claro da ruga espiracular à área subdorsal, marrom-avermelhado com pontuação esbranquiçada no dorso e avermelhado na área ventral; faixas longitudinais dorsais sinuosas; escolo preto, espiniforme, inclinado para trás, no dorso de $\mathrm{A} 3$ próximo ao limite posterior, e outro semelhante, menor e igualmente localizado em A5. Ruga espiracular dilatada, limaciforme, granulosa, com a borda serrilhada e repleta de cerdas esbranquiçadas. A larva ao ser incomodada projeta a glândula jugular, vermelha, anterior às pernas protorácicas. Comprimento $36 \mathrm{~mm}$. Duração 11 dias.

Quarto ínstar (Fig. 5). Cabeça castanho-clara, clípeo e parte externa das mandíbulas esbranquiçadas; são pretas as suturas, a borda interna das mandíbulas e os estemas. Três faixas formadas com pontículos pretos: a primeira começa logo abaixo do escolo látero-ventral e termina próximo às antenas; a mediana parte da base do escolo dorsal até a área estematal, e a última da borda posterior deste último escolo à base da fronte. Sobre a sutura mediana há uma quarta faixa com aspecto semelhante às anteriores. Desaparecem as faixas longi- tudinais do corpo, agora como manchas mais escuras que o restante do tegumento. Área ventral mais clara e translúcida. Prolongamentos da placa suranal na maior porção basal dorsalmente da mesma coloração geral do tegumento e marrom-escuros no restante. Espiráculos oblongos, castanho-claros, peritrema preto. Demais características como no ínstar anterior. Comprimento 59,5 mm. Duração 15 dias.

Quinto ínstar (Figs 6-8). Cabeça semelhante ao ínstar anterior, com as cerdas mais longas e adensadas lateralmente e sobre os escolos menores (Fig. 7). Tegumento castanho-claro, levemente róseo, áspero, formado com grânulos arredondados de coloração esbranquiçada; mancha dorsal oliváceo-escura com contornos sagitiformes mais destacados de A2 à placa suranal; faixas oliváceas longitudinais menos destacadas, sendo uma supra-espiracular e a outra subdorsal, ambas com manchas mais escuras puntiformes e desordenadas. Ruga espiracular com a borda mais serrilhada por causa do maior número de grânulos e de suas cerdas. Pequena verruga dorsal em A3 e A5 substitui os respectivos escolos. Os grânulos dorsais, os subventrais e os das pernas abdominais são bordados de preto, estes últimos com cerdas esbranquiçadas. Prolongamento da placa suranal da coloração geral do tegumento, formada com calosidades espiniformes, cada uma com uma cerda esbranquiçada apical (Fig. 8). Algumas larvas menos desenvolvidas tiveram um ínstar extra, com o natural prolongamento do período larval, mas conservaram as mesmas características morfológicas e cromáticas do quinto ínstar. Comprimento 100 mm. Duração 37-69 dias.

\section{Pupa (Figs 9-10)}

A morfologia da pupa é muito semelhante às de Opsiphanes quiteria quirinus Godman \& Salvin, 1881 (CuвERo 1985) e O. invirae amplificatus Stichel, 1904; e diferente de Eryphanis aesacus (Herrich-Schaeffer, 1850) (CuBERo 1985) e E. automedon automedon (Cramer, 1775) (DiAs-Filho 1979).

Gradativamente cônica a partir de A3. Áreas cefálica e pronotal quadrangulares. Vértice cefálico largamente bífido. Dorsalmente o mesotórax e área lateral do metatórax até A3, encumeadas. Tegumento castanho-amarelado, claro, fosco, com marmorizações e estrias castanho-escuras, estas longitudinais nos segmentos abdominais, ambas mais espalhadas e com mais destaque do limite lateral do vértice à A2 e da área espiracular de A4 ao cremaster. Espiráculos da cor predominante do tegumento, peritrema castanho-escuro. Cremaster triangular, rugoso, ganchos pretos. Comprimento $45 \mathrm{~mm}$; largura maior $16 \mathrm{~mm}$. Período pupal 17 dias.

\section{Dados bionômicos}

No Mato Grosso as larvas foram alimentadas com Dendrocalanus giganteus Munro e com Phyllostachys aurea A. \& C. Rivieri (Poaceae) e em Minas Gerais com os bambus P. aurea e Bambusa vulgaris Schrad. O ciclo de ovo até adulto (no Mato Grosso) foi de 115 dias para as larvas que tiveram cinco ínstares e de 147 dias para as poucas que tiveram um ínstar extra. Os adultos 

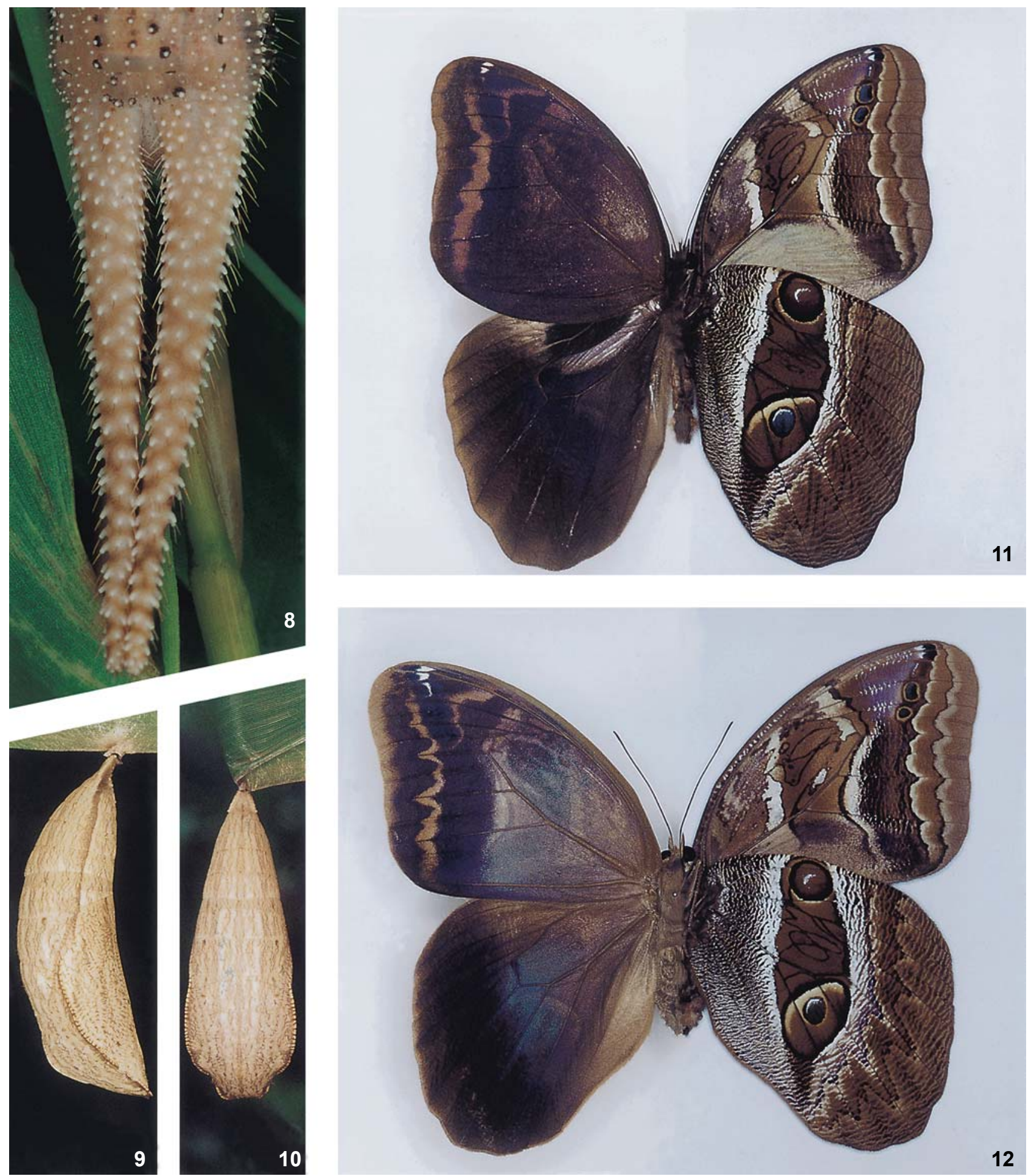

Figuras 8-12. Caligopsis seleucida: (8) último segmento abdominal e placa suranal da larva de $5^{\circ}$ ínstar, vista dorsal; (9-10) pupa: (9) vista lateral; (10) vista dorsal; (11-12) adultos: (11) macho, extensão alar 110 mm; (12) fêmea, extensão alar 120 mm, metade esquerda vista dorsal e metade direita vista ventral.

Revista Brasileira de Zoologia 21 (3): 593-597, setembro 2004 
(Figs 11-12) apresentam os mesmos hábitos verificados para espécies do gênero Eryphanis Boisduval, 1870 que voam durante o crepúsculo e alimentam-se principalmente de frutos em decomposição, seiva excretada por árvores atacadas por larvas xilófagas, e excrementos.

\section{AGRADECIMENTOS}

À Dra. Mirna Martins Casagrande por apoio e sugestões valiosas ao manuscrito; aos amigos Dr. Olaf H. H. Mielke, Dr. Keith S. Brown Jr. e Dr. Luiz S. Otero pela atenção dispensada a nós, pesquisadores autônomos.

\section{REFERÊNCIAS BIBLIOGRÁFICAS}

Blandin, P. 1974. Etude de Caligopsis seleucida (Hewitson) et considérations sur le genre Caligopsis Seydel (Brassolidae). Alexanor, Paris, 8 (4): 185-189, (5): 225-231.

Cubero, R. 1985. Notes on the life cycle and natural history of Opsiphanes quiteria quirinus Godman and Eryphanis aesacus buboculus Butler (Brassolidae). Journal of the Lepidopterists' Society, Los Angeles, 39 (1): 33-42.

D'ABRERA, B. 1987. Butterflies of Neotropical Region. Part III: Brassolidae, Acraeidae \& Nymphalidae (Partim). Victoria, Hill House, p. 386-525.

Dias-Filho, M.M. 1979. Morfologia e biologia de Eryphanis polyxena polyxena (Meerburgh, 1775) (Lepidoptera, Satyridae, Brassolinae). Revista Brasileira de Entomologia, São Paulo, 23 (4): 267-274.

Fruhstorfer, H. 1924. 5. Familie Brassolidae, p. 312-313. In: A. SeITz (Ed.) Die GrossSchmetterlinge der Erde. Stuttgart, Alfred Kermen, VIII+1141p.

Otero, L.S. \& L.C. Marigo. 1992. Borboletas de Carajás. Butterflies of Carajás. Rio de Janeiro, Companhia Vale do Rio Doce, 76p.

Robbins, R.K.; G. Lamas; O.H.H. Mielke; D.J. Harvey \& M.M. CasaGRANDE. 1996. Taxonomic composition and ecological structure of the species-rich butterfly community at Pakitza, Parque Nacional del Manu, Perú, p. 217-252. In: D.E. WiLson \& A. SANDOVAL (Eds). Manu. The biodiversity of Southeastern Peru. La biodiversidad del sureste del Peru. Washington, D.C., National Museum of Natural History, Editorial Horizonte, 679p.

Seydel, C. 1924. Eryphanis seleucida (Hew.) Männchen (Lep. Brassol.). Neue Beiträge zur systematischen Insektenkunde, Berlin, 3 (4): 30-32.

Stichel, H.F.E.J. 1909. Brassolidae. Das Tierreich, Berlin, 244p.

Travassos, L.P. \& E. May. 1941. Lepidópteros neotropicais. Coleção Julius Arp. Rio de Janeiro, Museu Nacional, 23p.

ZERNY, H. 1940. Über Caligopsis seleucida Hew. (Lep. Brassolidae). Zeitschrift des wiener Entomologen-Vereines 25 (8): 150152.

Recebido em 04.XI.2003; aceito em 26.VII.2004. 